\title{
Azole Resistance and ERG11 464 Polymorphism in Oral Candida albicans Clinical Strains Isolated in Sardinia
}

\author{
Germano Orrù $^{*}, 1$, Vincenzo Piras ${ }^{1}$, Maria Laura Ciusa ${ }^{1}$, Flavia Taccori ${ }^{1}$, Maria Barbara Pisano ${ }^{2}$, \\ Caterina Montaldo ${ }^{1}$, Sofia Cosentino ${ }^{2}$ and Maria Elisabetta Fadda ${ }^{2}$ \\ ${ }^{I}$ DNA Sequencing Service (DSS), Dipartimento di Chirurgia e Scienze Odontostomatologiche, Universita' degli Studi di \\ Cagliari, Cagliari, Italy \\ ${ }^{2}$ Dipartimento di Biologia Sperimentale, Sezione di Igiene, Universita' degli Studi di Cagliari, Cagliari, Italy
}

\begin{abstract}
The in vitro activity of three different azoles (fluconazole, FLC, voriconazole, VRC and ketoconazole, KTC) was determined and correlated with the single nucleotide polymorphisms (SNPs) in a "hot spot" region of the ERG11 gene in a collection of 52 arbitrarily selected C. albicans strains isolated from Sardinian subjects with oropharyngeal candidiasis. Among the strains evaluated, 23.1\% were resistant, 9.6\% Sensible Dose Dependent (SDD) and 67.3\% susceptible to FLC. Among the FLC resistant strains, $83.3 \%$ were also cross-resistant to VRC (10/12) and 66.6\% to KTC (8/12). The homozygous point mutation G464S was only detected in four out of five SDD to fluconazole strains. These data showed that the resistance of Candida albicans to azoles and the mutation at codon 464 of ERG11 are not associated. In addition the results also indicate a high prevalence of azole-resistant and cross resistant strains among these patients.
\end{abstract}

\section{INTRODUCTION}

Oral candidiasis is an important and frequent nosologic entity of the buccal cavity; in most cases it is caused by the pathogenic action of C. albicans. Treatment of C. albicans infections has been greatly facilitated since the introduction of azole antifungal agents. However, recently the isolation of a considerable percentage of azole-resistant strains has become a significant clinical problem, particularly in immunocompromised or debilitated patients [1-2]. Currently very few publications have described the azole resistance pattern for clinical oral isolates of C. albicans, particularly for patients arbitrarily recruited in dental care units [3].

A variety of mechanisms or combinations of mechanisms are associated with the development of azole drug resistance in C. albicans [4-7]. One of these molecular mechanisms includes single nucleotide polymorphisms (SNPs) in the gene $E R G 11$, which encodes the target enzyme of the azoles, the cytochrome P-450 lanosterol 14 alpha-demethylase (CYP51A1). Over the last few years, a considerable number of point mutations in ERG11 gene have been associated with azole antifungal resistance in clinical isolates of $C$. albicans, by studies using in vitro sterol biosynthesis with cell-free extracts and in spectrophotometric studies with recombinant proteins [8-12]. In particular, Marichal et al. [13] have listed the ERG11 sequences in azole-resistant isolates of C. albicans. They found the majority of the mutations in three regions, from amino acids 105 to 165,266 to 287 and 405 to 488 , suggesting the existence of three hotspot regions. One of the mutations most frequently associated with azole

*Address correspondence to this author at the Dipartimento di Chirurgia e Scienze Odontostomatologiche, Università degli Studi di Cagliari, Via Binaghi 4, 09121 Cagliari, Italy; Tel: +39 070537413; Fax: +39 070 537437; E-mail: orru@unica.it resistance was the substitution G464S, causing a modification of the heme environment $[11,14]$.

In recent years, the development of techniques to rapidly predict susceptibility to antifungal drug treatment has been under active investigation. Despite the existence of a number of useful methods for mutation detection, a critical goal in biomedicine is the ability to sequence a large number of DNA samples rapidly and accurately. In this paper we describe the application of a Pyrosequencing method [13-16] for detecting point mutations in a short ERG11 fragment (codons 464 to 474) in 52 oral clinical isolates of C. albicans with different susceptibility profile to fluconazole, voriconazole and ketoconazole.

\section{MATERIALS AND METHODOLOGY}

\section{Clinical Samples}

An oral swab was collected from 52 Sardinian subjects, aged from 59 to 76 (mean 65), recruited over seven years (2000-2006) at the Department of Dental Disease Prevention (University of Cagliari). All the subjects had given informed consent to take part in the microbiological analysis. None of the patients who took part in the experiments had undergone antimycotic therapy during the previous month. These subjects reported a non-immunocompromised status. The samples were taken by brushing the lesions with a sterile swab. These specimens were plated in Sabouraud glucose agar for $48 \mathrm{~h}$ at $35^{\circ} \mathrm{C}$ (Microbiol, Cagliari, Italy). The colonies were identified with an API ID32C system (Biomerieux, St Louis, $\mathrm{MO}$ ) and maintained at $-20^{\circ} \mathrm{C}$ in skim milk (Oxoid, Basingstoke, UK).

\section{Antifungal Susceptibility Testing}

Antifungal susceptibility tests were performed in sterile flat-bottom 96-well microplates, according to the methodology recommended by the Clinical and Laboratory Standards 
Institute (CLSI, formerly the National Committee for Clinical Laboratory Standards [NCCLS]) document M-27 A2 [17]. Pure standard compounds of the following antifungal drugs were tested: fluconazole (FLC) and voriconazole (VRC), generously donated by Pfizer (New York, USA) and ketoconazole (KTC) (RBI, Natick, MA, USA). The interpretative breakpoints for FLC and VRC were determined according to the recent CLSI guide (CLSI subcommittee, January 2005 meeting), considering isolates with a MIC >64 $\mu \mathrm{g} / \mathrm{ml}$ for $\mathrm{FLC}$ and $>4 \mu \mathrm{g} / \mathrm{ml}$ for $\mathrm{VRC}$ as resistant, isolates with a MIC between 16 and $32 \mu \mathrm{g} / \mathrm{ml}$ for FLC and $2 \mu \mathrm{g} / \mathrm{ml}$ for VRC as Susceptible Dose Dependent (SDD) and isolates with a MIC $<8 \mu \mathrm{g} / \mathrm{ml}$ for FLC and $<1 \mu \mathrm{g} / \mathrm{ml}$ for VRC as susceptible. Due to a lack of consensus about the definition of MIC breakpoints for KTC, arbitrary values were established according to previous studies: resistant for isolates with a MIC $>1 \mu \mathrm{g} / \mathrm{ml}$, SDD for isolates with a MIC between 0.25 and $0.50 \mu \mathrm{g} / \mathrm{ml}$ and susceptible for isolates with a MIC $<0.125 \mu \mathrm{g} / \mathrm{ml}$ [18]. Tests were repeated at least three times on three separate days. C. krusei (ATCC 6258) and $C$. parapsilosis (ATCC 22019) were included as quality control strains.

\section{Primer Design}

Oligonucleotides used in this procedure were designed using the ERG11 sequence of C. albicans ATCC 44858 obtained from the NCBI database (GenBank accession number AF153844). Possible oligonucleotide dimer formation, selfcomplementarity and annealing temperatures for PCR and Pyrosequencing reaction were calculated using the Oligo program vs.6 (MedProbe, Oslo, Norway). The prediction of the $\mathrm{T}_{\mathrm{m}}$ DNA secondary structure for the Erg11 fragment was calculated with the mfold program: http://mfold.bioinfo.rpi. $\mathrm{edu} /[19]$. $\mathrm{T}_{\mathrm{m}}$ folding conditions were: $\mathrm{Na}^{+} 1 \mathrm{~mol} \mathrm{l}^{-1} ; \mathrm{Mg}^{2+}, 0$ mol $1^{-1}$; hybridization temperature, $37^{\circ} \mathrm{C}$. Pyrosequencing PCR primers: OG 212 (5'GATTATGGGTTTGGGAAAGT3'), position 1336-1355) and OG237 (5'-AATCAGGGTCAGGCACTTT-3') position 1513-1495) were designed to flank a region of $178 \mathrm{bp}$ of the ERG11 gene (nu- cleotide positions 1336 to 1513 of the 1587 bp long gene). Oligo OG 237 was biotinylated at its 5 prime end. The pyrosequencing primer was OG 238 (5'-GTTTCTTCACCTTATTTACCATT-3' position 1366-1388).

\section{Erg11 Fragment Amplification by PCR}

A 178 bp fragment consisting of the $E R G 11$ gene was amplified by PCR from cell suspension ( $\left.10^{7} \mathrm{CFU} / \mathrm{ml}\right)$. Amplification was performed in $50 \mu \mathrm{l}$ reaction volumes using MegaMix 2MM-5 (Microzone Limited, West Sussex, UK) according to the manufacturer's instructions. The mixture contained: $5 \mu_{\mathrm{mol} \mathrm{I}^{-1}}$ of each primer (OG212 and 5'biotinylated $\mathrm{OG} 237), 2 \mathrm{mmol}{ }^{-1} \mathrm{MgCl}_{2}$, and $1 \mu \mathrm{l}$ of cell suspension. The thermocycler profile was as follows: an initial denaturation at $95^{\circ} \mathrm{C}$ for $5 \mathrm{~min} ; 35$ cycles consisting of $48^{\circ} \mathrm{C}$ for $1 \mathrm{~min}, 68^{\circ} \mathrm{C}$ for $3 \mathrm{~min}$ and $40 \mathrm{sec}, 95^{\circ} \mathrm{C}$ for $1 \mathrm{~min}$ and a final extension at $68^{\circ} \mathrm{C}$ for $10 \mathrm{~min}$.

\section{PCR Sample Preparation for the Pyrosequencing}

Biotinylated PCR products were immobilized on streptavidin-coated Sepharose beads (Amersham Biosciences, Milano). Fifty $\mu \mathrm{l}$ of binding buffer (Pyrosequencing AB, Uppsala, Sweden) were added to $50 \mu \mathrm{l}$ of the PCR product; then $4 \mu \mathrm{l}$ of streptavidin-coated Sepharose beads were added, and the solution was vigorously mixed at room temperature for 10 minutes. The mixture was transferred to a filter plate (Millipore, Amsterdam, NL) and the binding buffer was removed by vacuum. The biotinylated DNA attached to the streptavidin-coated Sepharose beads was denaturated in 50 $\mu 1$ of denaturation buffer (Pyrosequencing AB, Uppsala, Sweden) for $1 \mathrm{~min}$. The Denaturation buffer was removed by vacuum and the DNA was washed twice with $150 \mu \mathrm{l}$ of Wash Buffer (Pyrosequencing AB, Uppasala, Sweden). The ssDNA was resuspended in $50 \mu$ of annealing buffer (Pyrosequencing AB, Uppsala, Sweden). Pyrosequencing reaction. The annealing reaction was performed at $60^{\circ} \mathrm{C}$ for 5 minutes on a thermoblock (MPM Instruments, Milano, Italy). The annealing mixture contained: $35 \mu \mathrm{l}$ of ssDNA suspension, $5 \mu \mathrm{mol} \mathrm{l}^{-1}$ of OG238 sequence primer, $1,5 \mathrm{mmol}^{-1}$ $\mathrm{MgCl}_{2}$. After the annealing reaction, $2 \mu \mathrm{l}$ of SSB reagent (Pyrosequencing $\mathrm{AB}$, Uppsala, Sweden) was added to the mixture. Pyrosequencing was performed at $25^{\circ} \mathrm{C}$ in an automated 96-well Pyrosequencing instrument using a PSQ ${ }^{\mathrm{TM}} 96$ SQA Kit containing enzymes, substrates and nucleotides for cyclic addition, according to the manufacturer's instructions (Pyrosequencing AB, Uppsala, Sweden). Pyrosequencing data were evaluated using Peak Height Determination Software v1.1 (Pyrosequencing AB, Uppsala, Sweden).

\section{RESULTS AND DISCUSSION}

A collection of clinical C. albicans isolates was examined for drug susceptibility testing, and by a real time sequencing method (Pyrosequencing). Table 1 shows that of the 52 strains evaluated, 12 were resistant, 5 SDD and 35 susceptible to FLC. Among the FLC resistant strains, 10 were also cross-resistant to VRC and 8 to KTC. The point mutation GGT464AGT, leading to the aminoacid substitution Glycine with Serine was detected in four of the five strains demonstrating fluconazole MICs of 16-32 $\mu \mathrm{g} / \mathrm{ml}$ (the exception was CA 74). Among these, CA 75 and CA 64 strains were also resistant/SDD to $\mathrm{VRC}$ and CA64 to KTC; on the contrary, CA 27 and CA 53 strains were susceptible to the other triazole agents. A wild type profile was present in all remaining strains (48/52 strains).

Fig. (1) shows representative pyrograms identifying the wild type (a) and the mutated codon 464 (b) in the ERG11 gene section under analysis. During the cyclic nucleotide dispensation strategy, nucleotides were repeatedly added in the order A, C, G, T. With the use of Pyrosequencing we were able to distinguish between strains that were hetero- or homozygous for the presence of the mutation [15]. Profile $b$ was identical in all four mutated strains and the peak height, indicating the G/A polymorphism, shows a homozygous point mutation.

Recently, molecular assays have been developed to detect mutations associated with antifungal resistance in $C$. albicans. These include the use of specific hybridisation probes for use with the LightCycler, a line probe assay and PCR restriction fragment length polymorphism analysis [9, $10,20-22]$. In this work, we have investigated the possibility of typing single-base variations in the ERG11 fragment of $C$. albicans strains by using a recently developed sequencing technique, called "Pyrosequencing", which allows for rapid real-time identification of nucleotides. We have focused our 
study on the sequence between nucleotide positions 1336 to 1513 of the 1587 bp long ERG11 gene in which three point mutations (G464S, G465S and R467K) are located, previously described in $C$. albicans FLC-resistant strains $[9,13]$. All these amino acids are located near the heme binding site, and the mutations probably result in structural or functional alterations. Among these, G464S is the most frequent mutation associated with azole resistance $[11,14,20,22]$ while few reports exist regarding the others $[8,9,12,13]$. We observed homozygous mutation G464S in only 4 out of 5 of the isolates for which the MICs of FLC were between 16 and 32 $\mu \mathrm{g} / \mathrm{ml}$ (SDD strains), while no changes were shown in the ERG11 nucleotide sequence in FLC-resistant or susceptible isolates. Moreover, when the MICs of the other azole derivatives were examined in these mutant strains, only one KTCresistant and one VRC-resistant strain were found. Our results seem to support the hypothesis that the resistance of Candida albicans to azoles and the Gly-->Ser mutation at codon 464 of ERG11 are not associated.

a

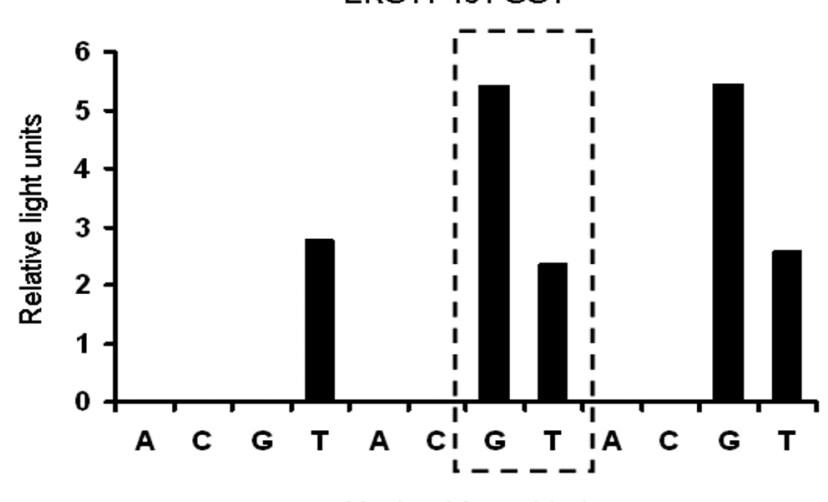

Nucleotides added

b

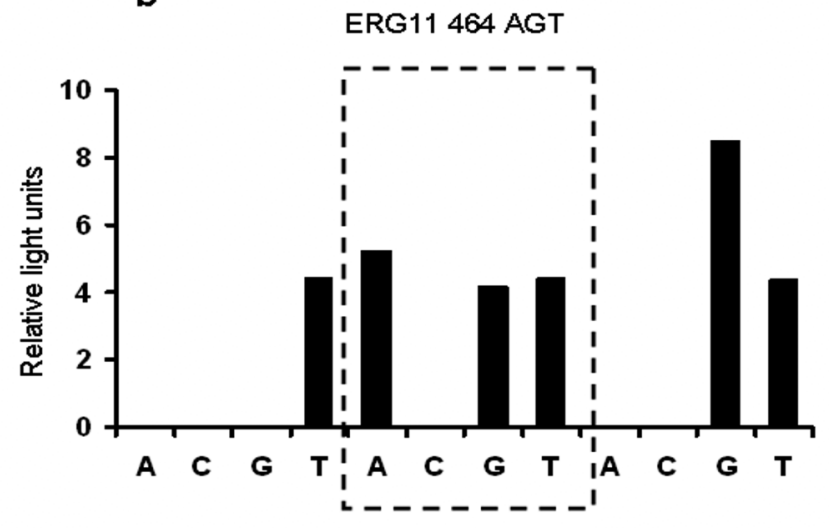

Nucleotides added

Fig. (1). Pyrograms obtained with ERG11 fragment: allele with codon 464 wild-type (a) and mutated codon 464 (b).

Current therapeutic strategy for infection control in patients with oral Candidiasis, foresees initial treatment with Nystatin or Myconazole, and a subsequent local application of Fluconazole (FLC) or Ketoconazole (KTC) as an alternative drug, particularly when extension into the esophagus is suspected. In some clinical studies Fluconazole was shown
Table 1. Correlation Between the MICs of Three Different Azoles and Mutations Found in the ERG11 Analyzed Fragment, Isolates are Ordered Sequentially by Fluconazole-Resistance Values

\begin{tabular}{|c|c|c|c|c|}
\hline \multirow{2}{*}{ Isolate } & \multicolumn{3}{|c|}{$\mathrm{MIC} \mu \mathrm{g} / \mathrm{ml}$} & \multirow{2}{*}{$\frac{E R G 11}{\text { Profile }}$} \\
\hline & FLC & VRC & KTC & \\
\hline CA 21 & $>64$ & $>8$ & 4 & $\mathrm{Wt}$ \\
\hline CA 25 & $>64$ & $>8$ & 4 & $\mathrm{Wt}$ \\
\hline CA 49 & $>64$ & $>8$ & 8 & $\mathrm{Wt}$ \\
\hline CA 95 & $>64$ & $>8$ & 16 & $\mathrm{Wt}$ \\
\hline CA 97 & $>64$ & $>8$ & $>16$ & $\mathrm{Wt}$ \\
\hline CA 100 & $>64$ & $>8$ & $>16$ & $\mathrm{Wt}$ \\
\hline CA 42 & $>64$ & $>8$ & $<0,03$ & $\mathrm{Wt}$ \\
\hline CA 47 & $>64$ & $>8$ & $<0,03$ & $\mathrm{Wt}$ \\
\hline CA 62 & $>64$ & $>8$ & $<0,03$ & $\mathrm{Wt}$ \\
\hline CA 72 & $>64$ & 0,5 & 16 & $\mathrm{Wt}$ \\
\hline CA 89 & $>64$ & $>8$ & $<0,03$ & $\mathrm{Wt}$ \\
\hline CA 91 & $>64$ & $<0,015$ & 2 & $\mathrm{Wt}$ \\
\hline CA 27 & 32 & 0,5 & $<0,03$ & G464S \\
\hline CA 64 & 32 & 1 & 8 & G464S \\
\hline CA 75 & 32 & 4 & 0,06 & G464S \\
\hline CA 53 & 16 & 0,5 & 0,06 & G464S \\
\hline CA 74 & 16 & 0,03 & $<0,03$ & $\mathrm{Wt}$ \\
\hline CA 57 & 2 & 0,03 & $<0,03$ & $\mathrm{Wt}$ \\
\hline CA 66 & 2 & 0,03 & $<0,03$ & $\mathrm{Wt}$ \\
\hline CA 80 & 2 & 0,25 & $<0,03$ & $\mathrm{Wt}$ \\
\hline CA 11 & 1 & $>8$ & $<0,03$ & $\mathrm{Wt}$ \\
\hline CA 33 & 1 & 0,03 & $<0,03$ & $\mathrm{Wt}$ \\
\hline CA 36 & 1 & $>8$ & 16 & $\mathrm{Wt}$ \\
\hline CA 51 & 1 & 0,06 & $<0,03$ & $\mathrm{Wt}$ \\
\hline CA 67 & 1 & $<0,015$ & $<0,03$ & $\mathrm{Wt}$ \\
\hline CA 68 & 1 & 0,03 & $<0,03$ & $\mathrm{Wt}$ \\
\hline CA 86 & 1 & 0,03 & $<0,03$ & $\mathrm{Wt}$ \\
\hline CA 87 & 1 & $<0,015$ & $<0,03$ & $\mathrm{Wt}$ \\
\hline CA 8 & 0,5 & $>8$ & $<0,03$ & $\mathrm{Wt}$ \\
\hline CA 9 & 0,5 & $>8$ & $<0,03$ & $\mathrm{Wt}$ \\
\hline CA 50 & 0,5 & $<0,015$ & 8 & $\mathrm{Wt}$ \\
\hline CA 6 & 0,5 & 0,06 & $<0,03$ & $\mathrm{Wt}$ \\
\hline CA 24 & 0,5 & 0,03 & $<0,03$ & $\mathrm{Wt}$ \\
\hline CA 34 & 0,5 & 0,03 & $<0,03$ & $\mathrm{Wt}$ \\
\hline CA 48 & 0,5 & $<0,015$ & $<0,03$ & $\mathrm{Wt}$ \\
\hline CA 56 & 0,5 & $<0,015$ & $<0,03$ & $\mathrm{Wt}$ \\
\hline CA 58 & 0,5 & $<0,015$ & $<0,03$ & $\mathrm{Wt}$ \\
\hline CA 60 & 0,5 & $<0,015$ & $<0,03$ & $\mathrm{Wt}$ \\
\hline CA 70 & 0,5 & $<0,015$ & $<0,03$ & $\mathrm{Wt}$ \\
\hline CA 73 & 0,5 & 0,03 & $<0,03$ & $\mathrm{Wt}$ \\
\hline CA 76 & 0,5 & $<0,015$ & $<0,03$ & $\mathrm{Wt}$ \\
\hline CA 79 & 0,5 & $<0,015$ & $<0,03$ & $\mathrm{Wt}$ \\
\hline $\mathrm{CA} 4$ & 0,25 & $<0,015$ & $<0,03$ & $\mathrm{Wt}$ \\
\hline CA 5 & 0,25 & 2 & $<0,03$ & $\mathrm{Wt}$ \\
\hline CA 12 & 0,25 & $<0,015$ & $<0,03$ & $\mathrm{Wt}$ \\
\hline CA 18 & 0,25 & 0,03 & $<0,03$ & $\mathrm{Wt}$ \\
\hline CA 19 & 0,25 & $<0,015$ & $<0,03$ & $\mathrm{Wt}$ \\
\hline CA 35 & 0,25 & 0,03 & $<0,03$ & $\mathrm{Wt}$ \\
\hline CA 37 & 0,25 & $<0,015$ & $<0,03$ & $\mathrm{Wt}$ \\
\hline CA 26 & $<0,125$ & 0,06 & 16 & $\mathrm{Wt}$ \\
\hline CA 22 & $<0,125$ & $<0,015$ & $<0,03$ & $\mathrm{Wt}$ \\
\hline CA 28 & $<0,125$ & $<0,015$ & $<0,03$ & $\mathrm{Wt}$ \\
\hline
\end{tabular}

The azole MIC coordinates were: FLC: R $>64 \mu \mathrm{g} / \mathrm{ml}$, DDS 16-32 $\mu \mathrm{g} / \mathrm{ml}, \mathrm{S}<8 \mu \mathrm{g} / \mathrm{ml}$; VRC: R $>4 \mu \mathrm{g} / \mathrm{ml}$, DDS $2 \mu \mathrm{g} / \mathrm{ml}, \mathrm{S}<1 \mu \mathrm{g} / \mathrm{ml}$; KTC: R $>1 \mu \mathrm{g} / \mathrm{ml}$, DDS $0.25-0.50$ $\mu \mathrm{g} / \mathrm{ml}, \mathrm{S}<0.125 \mu \mathrm{g} / \mathrm{ml}$. (NCCLS, http://www.nccls.org/). 
to be superior to a Nystatin suspension for the treatment of oral thrush in otherwise healthy infants or in HIV-infected patients $[18,22]$. Recently, second-generation triazoles, such as Voriconazole (VRC) have been used in oral candidiosis. In particular this azole has a broad-spectrum activity against yeasts and moulds, including the Aspergillus species. A limited number of papers have described the azole susceptibility pattern for clinical isolates of $C$. albicans in the oral cavity from non- immunocompromised patients. The usual susceptibility patterns for oral C. albicans isolates, particularly with strains obtained from patients who had attended the dental hospital, showed a low resistance $(0.3 \%)$ against FLC [23]. In contrast, we described a relatively high rate of resistant strains isolated in the oral cavity in (apparently) nonimmunocompromised patients. In fact in the present study, among these antimicotic agents tested, a total of $12 \mathrm{C}$. albicans isolates were found to be resistant to fluconazole. Ten of the fluconazole-resistant isolates $(83.3 \%)$ and 4 out of 35 $(11,4 \%)$ of fluconazole-susceptible isolates were found to be resistant to voriconazole. In addition, the prevalence of resistance to ketoconazole in fluconazole-resistant Candida isolates was 8 out of $12(66,6 \%)$, and 4 were recorded in 40 FLC susceptible or DDS (10\%). The multi Drug resistant strains with VRC-FLC-KTC, pattern were 6/52 (11.5\%). These results showed a high presence of azole resistant (and cross resistant) C. albicans strains in Sardinian patients with oral thrush, in particular we have observed elevated MICs to the new triazole drug (VRC $n=14 / 52$ 26,9\%). Among the possible explanations, could be the typology (the age) and the role of these patients in drug therapy effectiveness, i.e not taking a full course of therapy.

\section{ACKNOWLEDGEMENTS}

We would like to thank: Pfizer Inc. for supplying the fluconazole and voriconazole. Dr. Elvira Meroni, Dr. Carlo Farachi from BIOSENSE S.r.l and Dr. Roberto Usai from DEPECO S.r.1 for technical support.

\section{REFERENCES}

[1] Lopez-Ribot JL, McAtee RK, Lee LN, et al. Distinct patterns of gene expression associated with development of fluconazole resistance in serial Candida albicans isolates from human immunodeficiency virus-infected patients with oropharyngeal candidiasis. Antimicrob Agents Chemother 1998; 42: 2932-7.

[2] White TC, Marr KA, Bowden RA. Clinical, cellular, and molecular factors that contribute to antifungal drug resistance. Clin Microbiol 1998; 11: 382-402.

[3] Kuriyama T, Williams DW, Bagg J, Coulter WA, Ready D, Lewis MA. In vitro susceptibility of oral Candida to seven antifungal agents. Oral Microbiol Immunol 2005; 20: 349-53.

[4] Franz R, Ruhnke M, Morschhäuser J. Molecular aspects of fluconazole resistance development in Candida albicans. Mycoses 1999; 42: 453-8.

[5] Morschhäuser J. The genetic basis of fluconazole resistance development in Candida albicans. Biochim Biophy Acta 2002; 1587: 240-8.
[6] Lupetti A, Danesi R, Campa M, Del Tacca M, Kelly S. Molecular basis of resistance to azole antifungals. Trends Molec Med 2002; 8: 76-81.

[7] Rogers PD, Barker KS. Genome-wide expression profile analysis reveals coordinately regulated genes associated with stepwise acquisition of azole resistance in Candida albicans clinical isolates. Antimicrob Agents Chemother 2003; 47: 1220-7.

[8] White TC. The presence of an R467K aminoacid substitution and loss of allelic variation correlate with an azole-resistant lanosterol $14 \alpha$ demethylase in Candida albicans. Antimicrob Agents Chemother 1997; 41: 1488-94.

[9] Sanglard D, Ischer F, Koyman L, Bille J. Aminoacid substitutions in the Cytochrome P-450 Lanosterol 14 $\alpha$-demethylase (CYP51A1) from azole-resistant Candida albicans clinical isolates contribute to resistance to azole antifungal agents. Antimicrob Agents Chemother 1998; 42: 241-53.

[10] Asai K, Tsuchimori N, Okonogi K, Perfect JR, Gotoh O, Yoshida Y. Formation of azole-resistant Candida albicans by mutation of sterol 14-demethylase P450. Antimicrob Agents Chemother 1999; 43: 1163-9.

[11] Kelly SL, Lamb DC, Loeffler J, Einsele H, Kelly DE. The G464S amino acid substitution in Candida albicans sterol $14 \alpha$-demethylase causes fluconazole resistance in the clinic through reduced affinity. Biochem Biophys Res Commun 1999; 262: 174-9.

[12] Lamb DC, Kelly DE, White TC, Kelly SL. The R467K amino acid substitution in Candida albicans sterol 14alpha-demethylase causes drug resistance through reduced affinity. Antimicrob Agents Chemother 2000; 44: 63-7.

[13] Marichal P, Koymans L, Willemsens S, et al. Contribution of mutations in the cytochrome P450 14 $\alpha$-demethylase (Erg11p, Cyp51p) to azole resistance in Candida albicans. Microbiology 1999; 145: 2701-13.

[14] Loffler J, Kelly SL, Hebart H, Schumacher U, Lass-Florl C, Einsele H. Molecular analysis of cyp51 from fluconazole-resistant Candida albicans strains. FEMS Microbiol Lett 1997; 151: 263-8.

[15] Ronaghi M, Uhlén M, Nyrén P. A sequencing method based on real-time pyrophosphate. Science 1998; 281: 363-5

[16] Isola D, Pardini M, Varaine F, et al. LONG-DRUG study group. A Pyrosequencing assay for rapid recognition of SNPs in Mycobacterium tuberculosis embB306 region. J Microbiol Methods 2005; 62: 113-20.

[17] NCCLS-National Committee for Clinical Laboratory Standards, Publication M27-A2. Reference method for broth dilution antifungal susceptibility testing of yeasts; approved standard. NCCLS 2002; 22: 1-29.

[18] Rodriguez-Tudela JL, Martinez-Suarez JV, Dronda F, Laguna F, Chaves F, Valencia E. Correlation of in vitro susceptibility test results with clinical response: a study of azole therapy in AIDS patients. J Antimicrob Chemother 1995; 35: 793-804.

[19] Zuker M. Mfold web server for nucleic acid folding and hybridization prediction. Nucleic Acids Res 2003; 31: 3406-15.

[20] Watts D, MacBeath JR. Automated fluorescent DNA sequencing on the ABI PRISM 310 Genetic Analyzer. Methods Mol Biol 2001; 167: $153-70$.

[21] Loeffler J, Hagmeyer L, Hebart H, Henke N, Schumacher U, Einsele H. Rapid detection of point mutations by fluorescence resonance energy transfer and probe melting curves in Candida species. Clin Chem 2000; 46: 631-5.

[22] Perea S, Lopez Ribot JL, Kirkpatrick WR, et al. Prevalence of molecular mechanisms of resistance to azole antifungal agents in Candida albicans strains displaying high-level fluconazole resistance isolated from human immunodeficiency virus-infected patients. Antimicrob Agents Chemother 2001; 45: 2676-84.

[23] Kuriyama T, Williams DW, Bagg J, Coulter WA, Ready D, Lewis MA. In vitro susceptibility of oral Candida to seven antifungal agents. Oral Microbiol Immunol 2005; 20: 349-53. 